\title{
Correlation Between the Fruit Position on the Plant and Seeds Quality Indices of Green Peppers (Capsicum annuum L.)
}

\author{
Gicuta SBIRCIOG ${ }^{1}$ \\ ${ }^{1}$ Research and Development Institute for Vegetable and Flower Growing Vidra, 077185 \\ *)Corresponding author, e-mail: ralldom@yahoo.com \\ BulletinUASVM Horticulture 72(2) / 2015 \\ Print ISSN 1843-5254, Electronic ISSN 1843-5394 \\ DOI:10.15835/buasvmcn-hort:11467
}

\begin{abstract}
During the 2013-2014 period in the frame of the experimental field of RDIVFG VIDRA, three green pepper varieties, created at the Plant Breeding Department of the Institute, were investigated under comparative plots for evaluation. Several observations and morphological determinations were carried out aiming the following indices: the germinative faculty (GF) and the germinative energy (GE). Depending on the formation order of the fruits on the plant, there were significant differences between the values of the main physiological indices of the seeds' quality, both for the germinative faculty of the seeds and for their germinative energy. Between the position of the fruit on the plant and the quality of the seeds it is a strong negative corelation, distinct significant, the value of the relation coefficient ( $r$ ) being over the values for P $5 \%$ and P $1 \%$.
\end{abstract}

Keywords: pepper, fruit position, germinative faculty, germinative faculty, seed quality.

\section{Introduction}

Ensuring the necessary seed quantities for the production extension of the biological material from the valuable varieties and hybrids, which may ensure the maintenance of their initial traits, implies permanently applying certain intervention methods and techniques, depending on the biological particularities of the species and cultivar (the variety or hybrid), in a well-defined system, bearing the name of "production of the seeds and seedling material" (Ciofu et al., 2003; Sbîrciog, 2003).

\section{Aims and objectives}

Starting from the premise that between the seeds' quality traits and the position/order of the fruits' formation on the mother plant there are certain connections (Demir, 1991; Ozlem and Benian, 2007), the work aims at assessing the seeds' quality parameters depending on the order of the formation on the mother plant, at three genotypes of sweet peppers 'Galben superior', 'Bârsan' and 'Vidra 9'.

\section{Materials and methods}

In order to establish some technological solutions of intervention aiming at increasing the seeds' quality, the biological material represented by the three types of sweet pepper, was studied in comparative plots for evaluation, located following the layered randomized blocks method, in four repetitions. To this end, there were several biometric determinations made aiming at establishing the following indices: the germinative faculty and the germinative energy. The assessment of the connections between the variables under study was achieved through synthetic numerical expressions, namely by correlation coefficients, while the significance of the differences between the variants under study was achieved by using the Duncan test.

\section{Results and Discussion}

The results obtained show the existence of certain distinctly significant negative correlations between the fruit's position on the plant and the seeds' main quality indices. Depending on the 
